\title{
Are Currency Exchange Rates Influenced by the Daily Option Expiry Levels?
}

\author{
A. Teder, P. Sander, and T. Mitt
}

\begin{abstract}
Option expiries and their influence on asset prices has been studied across several stock markets and derivatives markets. Current paper focuses on option expiries in the currency market which has not been studied so widely. The aim of the paper is to test whether daily currency exchange rates are influenced by option expiries, more specifically whether the exchange rate of a currency has a tendency to close near the weighted average of various currency option levels. For that purpose we calculate the weighted average price level of known option expiry levels and test a) whether the price moves towards the average expiry level during European trading day and b) whether the price is closer to the average expiry level at the time of expiration. We perform our tests on the most liquid currency pairs EUR/USD and USD/JPY. We conclude that there is no significant evidence that in average currency exchange rates are influenced by the daily option expiry levels.
\end{abstract}

Index Terms-Currency market, exchange rate manipulation, option expiries, price behavior.

\section{INTRODUCTION}

All participants of the currency market have an option to buy or sell call or put options to hedge their risk against a fluctuation in the exchange rate or to speculate with the expectation that the option contract would increase in value by the time of its expiry. For each option contract there is an underwriter who sells the contract to market participants (usually larger banks).

At the time of expiry settlement between the owner of the contract and the underwriter takes place. For put options if the exchange rate at expiry is lower than the strike price of the option contract the underwriter takes loss and owner of the contract takes profit which is equal to the difference in current exchange rate and strike price.

Since option contracts expiring at a certain time and date are a zero-sum game (for each contract somebody takes profit and somebody takes loss) it is beneficiary for a certain participant having an open position with option contracts if the price would move in the direction which is suitable for their needs.

For example for a participant who has underwritten a great number of put options is interested that the actual exchange rate would stay above the strike exchange rate until the time of expiry so they could keep the premium from selling the option contract and option contracts would expire worthless.

At the same time the buyer(s) of the contracts are interested that the actual exchange rate would stay below the strike exchange rate until the time of expiry so they could make profit from owning the contracts.

Manuscript received September 2, 2013; revised October 20, 2013 Allan Teder is with University of Tartu, Estonia (e-mail: allant@ut.ee).
The following analysis focuses on the speculative aspect of the option market. While there are a great number of participants who use options for risk management all the underwriters of the options and speculators are interested that the exchange rate would move in the direction that is beneficiary for them. From here several discussion points arise:

1) Since options are underwritten at various levels of exchange rates, there are multiple exchange rate levels where several market participants are interested that the exchange rate at the time of expiry would be fixed at the level of expiry so their loss would be minimal (if any) or at the level which is above or below the strike exchange rate of option contracts depending of the majority type of options underwritten (puts or calls);

2) All market participants can influence the exchange rate by buying or selling a certain amount of currency against other currency;

3) Levels that have more underwriters and larger number of options are levels of interest since several participants benefit from the same type of exchange rate behavior;

4) Since currency markets are very liquid and it is difficult for one participant to move the exchange rate significantly we assume that option expiry levels that are closer to the current price are more relevant and might influence exchange rates.

From the first discussion point we assume that since there are several option expiry levels the price tends to move towards the average expiry level and nearer expiry levels are more relevant.

From the second discussion point we assume that since option underwriters and speculative owners of option contracts have the capability to influence the exchange rate they might do so in order to benefit their option positions.

From the third discussion point we assume that large option expiry levels are more relevant and should be considered as more important influences to exchange rate.

From the fourth discussion point we assume that option-related buying and selling is limited and other factors influence the exchange rate more importantly.

The main idea of this paper is to analyze the price behavior during the trading day and test whether the exchange rate has a tendency to close nearer to the weighted average of various option levels. More specifically we test whether the price moves closer to the average expiry level at a certain trading day or not.

\section{LITERATURE OVERVIEW}

Currently there is no research done on currency option expiries and their effect on the exchange rate. The relevance 
of options however has been studied in other financial markets, most commonly for futures and stocks. First major studies were performed in US which is and has been the most developed financial market and which has a longer history of various financial instruments like futures and options.

Cinar [1] has found that option expiries do not have significant effect on major stock prices but volumes and volatility in option expiry day are above average. This is also statistically significant.

Bhattacharya [2] has studied options and their effect on bond prices and found that bond price volatility tends to rise before option expiries but there is no evidence that price behavior is somehow different from a regular trading day.

Hancock [3] has studied the effect of option expiries to S\&P-500 stock index futures and has found that volume and volatility tends to rise during option expiry days but no discrepancy in price behavior can be noted.

There are a growing number of studies investigating the effect of expiration of derivatives on price, volatility, and volume of the underlying shares in other markets than US. One of the first of such studies was conducted by Chamberlian, Cheung and Kwan [4] in Canada. Their findings confirmed the existence of both abnormal price patterns as well as abnormal trading volume in stock market around the expiration day. Subsequent studies in large well-developed markets (e.g. Pope and Yadav [5] in UK, Schlag [6] in Germany, Karolyi [7] in Japan) as well as in some emerging (e.g. Vipul [8], Maniar, Bhat and Maniyar [9] in India) markets have mostly reached to similar conclusions. A study performed by Gavious [10] on the Isreali market argued that there is significant difference in price behavior between normal trading days and option expiration days.

There are some countries where only abnormal volume but no significant price effect has been documented (e.g. Corredor, Lechon and Santamaria [11] in Spain), countries where no abnormal volume but some specific price patterns has been found (e.g. Chow, Yung and Zhang [12] in Hong-Kong) or countries and time periods where no expiration day effects have been confirmed (e.g. Chou, W. Chen and D. Chen [13] for Taiwan market during 1998-2002, Alkebäck and Hagelin [14] for Swedish market during 1988-1998). The authors of Swedish study suggested that this was due to longer settlement periods of options in Swedish market. For Taiwanese another study by Hsieh et al. [15] showed that once other factors such as open interest and institutional traders' activities are taken into account both volume and price behavior effects can be noted.

These mixed results observed in different markets have lead scientist to conclude that the existence of expiration day effects is dependent on market microstructure. Also it can be noted that most recent studies tend more towards supporting irregular price dynamics and increased volatility around option expiration dates compared to earlier ones. This might be related to the development of financial markets in general - access to markets has improved and the number of participants and trading volume has significantly increased.

Special attention has been given to the settlement procedures of derivative contracts, which may influence trading activities of hedgers and arbitrageurs. It has been argued (Ju et al. 2008) that expiration day effects may be more significant in countries adopting single price settlement (like US, Japan, or Canada) than in those using average price (like Hong-Kong or Taiwan). The latter has also been tested by Fung and Yung [16] where it was confirmed that once average price was used for settlement there was no significant connection between the structure of options and the next-day return. Also, other market microstructure aspects have been paid some attention, like short sale restrictions in cash markets (Vipul [8]) or absence of parallel option and future markets (Corredor, Lechon and Santamaria [11]). It has also been shown that the more index derivatives are listed, the stronger expiration day effect can be found (Ju, Lo and Wang [17]).

\section{DATA AND METhodology}

The daily option expiry levels used in this research are provided by an independent research and news publication website ForexLive [18] who publicly provides daily data of various currency option levels gathered from Bloomberg and Reuters.

In this paper the most liquid currency pairs USD/JPY and EUR/USD were tested. Liquidity in this paper refers to the total trading volume of various currencies. Reports show that in 2013 the total volume of EUR/USD was $24.1 \%$ and the total volume of USD/JPY was $18.3 \%$ of the total volume of global foreign exchange market [19]. As the reports by ForexLive also show these are also currency pairs that have the highest number of daily option expiry levels.

In total 134 trading days were tested for both currency pairs from the period of $1^{\text {st }}$ of February to $9^{\text {th }}$ of September 2013. During that time EUR/USD had a total of 876 option expiry levels amongst which 56 levels were large (over 500 million in base currency value of options expiring), in average there were over 6 option expiry levels for each trading day. During that time USD/JPY had a total of 1050 option expiry levels amongst which 154 levels were large, in average there were over 7 option expiry levels for each trading day.

Option levels are published by ForexLive each day before the European market opens at 07:00 (GMT) and options expire at 10 am Eastern Time (GMT-4). During the research period adjustments for daylight savings time was taken into account in the period of $11^{\text {th }}$ of March to $22^{\text {nd }}$ of March (in this period Eastern Time is GMT-5).

Since currency market does not have central clearing and the market is organized through interbank lending currency exchange rates of various providers differ somewhat. For this paper currency exchange rate data is provided by Armada Markets AS [20] who has liquidity provision agreements with Citibank, LMAX Exchange, NatWest and others.

The analysis is performed by comparing the European market opening exchange rate of a currency pair with the exchange rate of the same currency pair at the time of option expiry. It is then analyzed whether the exchange rate has moved closer to the weighted average of all option expiry levels where one could conclude that option levels have influenced the exchange rate. Weights have been derived from the logic of normal distribution and is described in the following. This follows the logic that theoretically if the exchange rate is influenced by option expiry levels the exchange rate would move towards option levels that are 
nearer to the current price.

Weighted average or target price level is calculated using following steps. First, standard deviation of the absolute value of the exchange rate daily return for the period is calculated (we assume that the exchange rate can move at an average rate during a trading day). The standard deviation is used to classify option expiry levels. Option expiry levels are divided into categories based on their relative difference from the exchange rate at European market opening at 07:00 am (GMT), after option expiry levels are announced earlier (roughly between 5 and 6 am (GMT)). The categories and their multiplier values derive implicitly from the logic of normal distribution where more approximate levels get larger weights. In this paper, the closer the expiry level is to the exchange rate at 07:00 am (GMT), the higher the probability of price moving to that level, hence higher the value of the multiplier. Weight multipliers for each option expiry level is calculated as follows.

$$
\left\{\begin{array}{l}
\frac{|e-p|}{y \cdot s t d} \geq 6 \rightarrow m=0.002 \\
6>\frac{|e-p|}{y \cdot s t d} \geq 5 \rightarrow m=0.01 \\
5>\frac{|e-p|}{y \cdot s t d} \geq 4 \rightarrow m=0.034 \\
4>\frac{|e-p|}{y \cdot s t d} \geq 3 \rightarrow m=0.088 \\
3>\frac{|e-p|}{y \cdot s t d} \geq 2 \rightarrow m=0.184 \\
2>\frac{|e-p|}{y \cdot s t d} \geq 1 \rightarrow m=0.3 \\
1>\frac{|e-p|}{y \cdot s t d} \geq 0 \rightarrow m=0.382
\end{array}\right.
$$

where

$$
\begin{aligned}
& p \text { - the exchange rate at 07:00 am (GMT); } \\
& e \text { - option expiry level; } \\
& y \text { - multiplier for determining the influence of difference } \\
& \text { between the exchange rate and option expiry level; } \\
& \text { std - historical standard deviation of the exchange rate } \\
& \text { movement; } \\
& m \text { - weight multiplier. }
\end{aligned}
$$

Multipliers for option expiry levels with higher volume (over 500 million in base currency value of options expiring) are then doubled. Then the weighted expiry levels are summed up and weighted average is calculated by dividing the sum of levels with the sum of multipliers.

After the target price (weighted average) is calculated, it is being used for two tests. First test finds out the percentage of the cases when the exchange rate moves closer to the target price by 10 am Eastern Time (GMT-4) at the time of options expiration. Second test finds out the percentage of cases where the exchange rate moves towards the price target.
Percentage found in first test is smaller than the percentage in second test. That is due to the fact that in order to move closer to the price target, exchange rate moves towards the price target. However, if the exchange rate moves towards the target, it may not close closer to the target by 10 am Eastern Time (GMT-4).

\section{RESUlts}

The results are presented by currency pairs and by behavior characteristics in the following table. When a currency pair's exchange rate moves closer to the average option level it means that the fixing value of the exchange rate was between the initial price and the average weighted option level. When a currency pair's exchange rate moves in the right direction it is fixed (closes at the expiration) at the level which surpasses the weighted expiration level but moves in the right direction while compared with the opening exchange rate at the European open.

It can be seen from the Table that in the case of EUR/USD if a larger amount of option expiries are taken into account (the size of $y$ increases or the number of closer option levels increases) the price tends to move closer to the average weighted option level and the correct direction for the move is slightly above $50 \%$.

The results are the opposite for USD/JPY where larger number of option levels lessens occasions where exchange rate moved closer to the average weighted expiry level.

On both occasions it can be seen that the amount of option levels taken into account with higher weight does not influence the direction of the move significantly. This can be interpreted in a way that the closest expiry levels influence the price behavior in the most significant way.

TABLE I: PRICE BEHAVIOR OF TWO CURRENCY PAIRS

\begin{tabular}{lccrc}
\hline \hline & \multicolumn{2}{c}{ EUR/USD } & \multicolumn{2}{c}{ USD/JPY } \\
\hline \hline $\mathrm{y}$ & Closer $(\%)$ & Direction $(\%)$ & Closer $(\%)$ & Direction $(\%)$ \\
\hline 0.25 & 24.1611 & 56.3758 & 44.9664 & 55.7047 \\
0.5 & 21.4765 & 53.6913 & 42.2819 & 55.7047 \\
0.75 & 23.4899 & 53.0201 & 40.9396 & 55.7047 \\
1.0 & 22.8188 & 53.6913 & 40.2685 & 55.7047 \\
2.0 & 38.9262 & 53.0201 & 34.8993 & 55.0336 \\
3.0 & 42.2819 & 53.6913 & 34.8993 & 55.0336 \\
\hline \hline
\end{tabular}

The results show that there is no significant relation between average weighted option levels, the fixing price and the exchange rate at the European market open. However this does not mean that option levels do not influence the exchange rate dynamics which is a basis for further research on this subject.

\section{ACKNOWLEDGMENT}

The authors would like to thank ForexLive.com team for agreeing with providing daily option expiry data for this research.

\section{REFERENCES}

[1] E. M. Cinar, "Evidence of the effect of option expirations on stock prices," Financial Analysts Journal, pp. 55-57, 1987.

[2] A. K. Bhattacharya, "Option expirations and treasury bond futures prices," The Journal of Futures Markets, vol. 7, no. 1, pp. 49-64, 1987. 
[3] G. D. Hancock, "Futures option expirations and volatility in the stock index futures market," The Journal of Futures Markets, vol. 11, no. 3 , pp. 319-330, 1991.

[4] T. W. Chamberlian, C. Sherman Cheung, and C. Y. C. Kwan, "Expiration-Day effects of index futures and options: some canadian evidence," Financial Analysts Journal, vol. 45, pp. 67-71, September-October 1989.

[5] P. F. Pope and P. K. Yadav. "The impact of option expiration on underlying stocks: the UK evidence," Journal of Business Finance and Accounting, vol. 19, pp. 329-344, April 1992.

[6] C. Schlag, "Expiration day effects of stock index derivatives in germany," European Financial Management, vol. 1, pp. 69-95, January 1996.

[7] A. G. Karolyi, "Stock market volatility around expiration days in Japan," Journal of Derivatives, vol. 4, pp. 23-43, Winter 1996.

[8] Vipul, "Futures and options expiration-day effects: the Indian evidence," The Journal of Futures Markets, vol. 25, pp. 1045-1065, November 2005.

[9] H. M. Maniar, R. Bhat, and D. M. Maniyar. "Expiration hour effect of futures and options markets on stock market - A case study on NSE (National Stock Exchange of India)," International Review of Economics and Finance, vol. 18, pp. 381-391, June 2009.

[10] I. Gavious, A. B. Shlomo, R. Yosef, M. Rosenboim. "Option trading manipulations on expiry date," Banking and Finance Letters 2009, vol. 1, issue 4, pp. 185-194. 2009.

[11] P. Corredor, P. Lechon, and R. Santamaria, "Option-Expiration Effects in Small Markets: The Spanish Stock Exchange," Journal of Futures Markets, vol. 21, pp. 905-928, October 2001.

[12] Y. Chow, H. H. M. Yung, and H. Zhang. "Expiration Day Effects: The Case of Hong Kong," Journal of Futures Markets, vol. 23, pp. 67-86, January 2003.

[13] H. Chou, W. Chen, and D. Chen. "The expiration effect of stock-index derivatives," Emerging Markets Finance and Trade, vol. 42, pp. 81-102, September-October 2006.

[14] P. Alkebäck and N. Hagelin, "Expiration day effects of index futures and options: evidence from a market with a long settlement period,' Applied Financial Economics, vol. 14, pp. 385-396, 2004.

[15] S. Hsieh and T. Ma, "Expiration-day effects: Does settlement price matter?" International Review of Economics and Finance, vol. 18, pp. 290-300, 2009.

[16] J. K. W. Fung and H. H. M. Yung. "Expiration-Day Effects - An Asian Twist," The Journal of Futures Markets, vol. 29, no. 5, pp. 430-450, 2009.
[17] S. Ju, K. Lo, and K. Wang. "Expiration Day Effects: Empirical Evidence from Taiwan," Journal of Global Business Issues, vol. 2, pp. 51-62, Spring 2008.

[18] ForexLive Blog. [Online]. Available: http://www.forexlive.com

[19] Bank of Interantional Settlements. (April 2013). Triennial Central Bank Survey. Foreign Exchange Turnover in April 2013: Preliminary Global Results. [Online]. Available: http://www.bis.org/publ/rpfx13fx.pdf

[20] Armada Markets AS. (2013). [Online]. Available: http://www.armadamarkets.ee

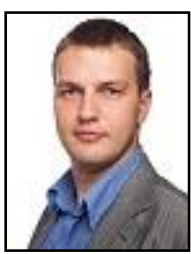

A. Teder is currently a Ph.D. student in the University of Tartu and is researching financial markets from the perspective of participants. He is employed by a start-up firm AT Systems OÜ which develops and applies trading algorithms.

His Current research focuses on testing various events that influence the price dynamics of a certain financial asset and perform relevant tests. Other areas of interest include pattern recognition and fundamental analysis of economic data.

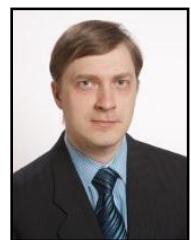

P. Sander holds Ph.D. in economics and is employed as an associated professor in finance at the University of Tartu.

His Current research focuses on company valuation in emerging markets, dividend and financing policy, tax-based trading strategies and other financial topics. He has also consulted firms in business valuation cases.

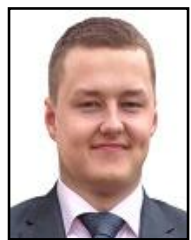

T. Mitt has currently bachelor's degree in economics and is researching financial markets from the perspective of participants. He is employed by a start-up firm AT Systems OÜ which develops and applies trading algorithms.

His Current research focuses on testing various events that influence the price dynamics of a certain financial asset and perform relevant tests. Other areas of interest include pattern recognition and fundamental analysis of economic data. 